\title{
ESTIMATION AND ANALYSIS OF USER IPP DELAYS USING BILINEAR MODEL FOR SATELLITE-BASED AUGMENTED NAVIGATION SYSTEMS
}

\author{
D. Venkata Ratnam \\ Department of ECE, K L University, Vaddeswaram, Guntur Dt, Andhra Pradesh, India \\ E-mail: ratnam2002v@gmail.com
}

Received 17 October 2012; accepted 20 May 2013

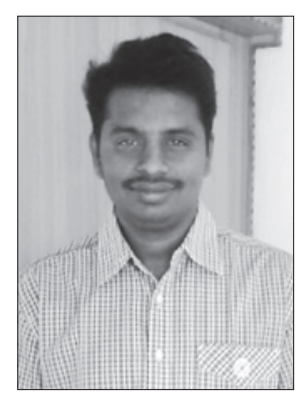

D. Venkata RATNAM, $P h D$.

Education: MSc (Electronics) degree from Andhra University, Faculty of Physics, A.P, India; M.Tech (Radar and Microwave engineering) degree from Andhra University, A.P, India, Faculty of Engineering. 2001 to 2003: PhD studies, JNTUH University, Hyderabad, A.P, India, Faculty of Electronics and Communication Engineering 2007-2011.

Affiliation and functions: 2003 to 2011: research assistant, junior research fellow, senior research fellow, senior research assistant, Research and Training Unit for Navigational Electronics, Osmania University, Hyderabad, A.P, India; 2011 - present, Associate Professor, Department of Electronics and Communication Engineering, KL University, Vaddeswaram, Guntur, A.P, India. Research interests: navigation electronics, global positioning system, space science, radio wave propagation.

Publications: author of 12 international and 4 national research papers and 23 national and international conference papers.

\begin{abstract}
Several countries are involved in developing satellite-based augmentation systems (SBAS) for improving the positional accuracy of GPS. India is also developing one such system, popularly known as GPS-aided geo-augmented navigation (GAGAN), to cater to civil aviation applications. The ionospheric effect is the major source of error in GAGAN. An appropriate efficient and accurate ionospheric time model for GAGAN is necessary. To develop such a model, data from 17 GPS stations of the GAGAN network spread across India are used in modelling. The prominent model, known as bi-linear interpolation technique, is investigated for user IPP (UIPP) delay estimation. User IPP delays for quiet, moderate and disturbed days are estimated. It is evident that measured mean UIPP delays closely follow estimated mean UIPP delays.
\end{abstract}

Keywords: GPS, ionospheric delay, total electron content, ionospheric pierce point.

\section{Introduction}

Stand-alone GPS (global positioning system) can meet the requirements of aircraft positioning applications, especially landing applications. Augmentation of GPS signals are necessary (Jakučionis, Giniotis 1998; Stankūnas et al. 2005; Jakučionis 1997). The USA and European countries have developed satellite-based augmentation systems for their aviation requirements. India is also developing a satellite-based augmentation system known as GPS-aided geo-augmented navigation (GAGAN) to cater to civil aviation applications in the Indian region (Kibe 2003; Suryanarayana Rao, Pal 2004). The GAGAN system is expected to be certified and operational in 2013. A suitable ionospheric model is essential for GAGAN applications to achieve CAT-I PA aircraft landing capacities. In GAGAN, two efficient ionospheric models are necessary: one for ionospheric grid point (IGP) delay estimation and the other for user ionospheric pierce point (IPP) delays. This imaginary ionospheric shell is divided into grids along latitude and longitude with a spacing of $5^{\circ} \times 5^{\circ}$. The points of intersection of these grids are called ionospheric grid points (IGP). The intersection of line of sight from GPS receiver to GPS satellite and the shell defined at a designated height of $350 \mathrm{~km}$ is known 
as an IPP. The existing ionosphere grid-based models are found to give better estimators in the mid latitude regions, where the spatial and temporal changes in the structure of the ionosphere are fairly smooth during magnetically quiet conditions (Lejeune et al. 2002; Būga 1999). However, in low latitude regions such as India and Brazil, the ionospheric conditions present more range delays due to spatial and temporal variations even during magnetically quiet times, as well as during disturbed ionospheric conditions. Several ionospheric models, namely planar fit, inverse distance weight (IDW), minimum mean square estimator (MMSE), and Kriging models, are investigated over the Indian region (Sarma et al. 2006). Other IGP delay models such as modified planar fit model (MPFM), MMSE, and spherical harmonics function models are also investigated over the Indian region (Sarma et al. 2009; Ratnam, Sarma 2006, Ratnam et al. 2011; Ratnam, Sarma, 2012). For user IPP (UIPP) delay estimation, the spatial interpolation algorithm is currently defined in the wide area augmentation system minimum operational standards (WAAS MOPS) and basically uses the four surrounding grids (WAAS MOPS... 1998). The ionospheric delay at IPP computed by the spatial interpolation method using the four surrounding IGP delays is known as UIPP. Spatial interpolation is the means of estimating the delays at unknown points by using the delays at known points. The bilinear model is one such prominent model. In this paper, the use of the bilinear model to estimate UIPP delay is presented. The bilinear model is also compared with other ionospheric grid models.

\section{Bilinear interpolation}

In the bilinear model, weight is a hyperbolic function, linear in latitude when longitude is fixed and vice versa. The delay at the user's IPP is the sum of the products of the vertical delays of the IGP $\left(5^{\circ} \times 5^{\circ}\right.$ square grid cell and their corresponding weights). The weights on the grid points can be estimated based on the locations of the IGPs and user's IPP. It is similar to Junkin's interpolation technique (Junkins et al. 1973). Bilinear interpolation can be used for only estimating the user IPP delay from three or four ionospheric grid points. The following considerations are taken for selecting the user's IPP delay.

\subsection{Considerations:}

a) all four grid points that surround the user's IPP are monitored simultaneously through geostationary earth orbit (GEO) satellite broadcast;

b) if four IGPs are selected and one of the four is identified as 'not monitored', then the three-point interpolation should be used if the user's pierce point is within the triangular region covered by the three corrections that are provided; c) if one of the four IGPs is identified as 'don't use', the entire square need not be used.

In the first two cases above, interpolation is possible. In the third case, since the integrity alarm message of 'don't use' has appeared in the message, it is advisable to drop that particular cell. Hence, interpolation is not possible in this case. The schematic diagram of the user IPP location in the square cell with four IGPs is shown in figure 1.

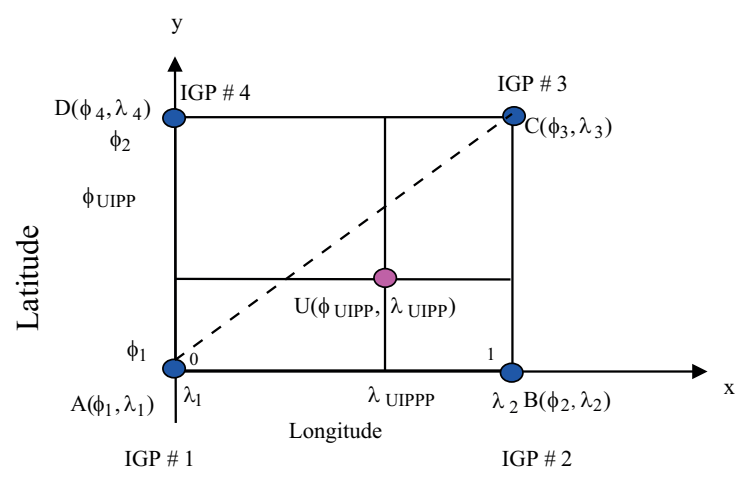

Fig. 1. User IPP location in square cell with four IGPs

\subsection{Case of four IGPs}

The weight of a particular grid point $\mathrm{D}_{\mathrm{v}}{ }^{\mathrm{i}}$ is given by the ratio of $\mathrm{A}$ and total cell area (WAAS MOPS... 1998).

$$
\mathrm{W}\left(\phi_{\mathrm{i}}, \lambda_{\mathrm{i}}\right)=\mathrm{A} / \text { Grid cell area, }
$$

where $\mathrm{A}$ is the opposite cell area given by

$$
\mathrm{A}=\left\{\Delta \phi^{\star} \Delta \lambda\right\}
$$

where $\Delta \phi$ and $\Delta \lambda$ are the difference between diagonally opposite IGP latitudes and longitudes and user's pierce points $\left(\phi_{\mathrm{u}}, \lambda_{\mathrm{u}}\right)$.

Using the weights, the delay at the user's pierce point can be estimated (WAAS MOPS... 1998).

$$
D_{v}^{u s e r}=\sum_{k=1}^{4} w_{i}(x, y) D_{v}^{i} \text {. }
$$

\section{Results and discussion}

The data of the dual frequency GPS receiver from 17 TEC stations across the Indian region are used to implement the bilinear interpolation algorithm for estimating user IPP delays. The locations of GPS TEC stations and data processing methodology are reported elsewhere (Sarma et al. 2009). Data from several days under various conditions such as magnetically quiet, moderate and disturbed conditions are considered for the analysis. The user requires IGP locations and corresponding vertical ionospheric delay values of the surrounding three or four IGPs. IGP vertical delays are estimated using the MMSE estimator (Ratnam, Sarma 2006). The estimated IGP delays are given as input to the bilinear model. The estimated and measured UIPP delays of several typical days are compared. The mean and standard deviations of UIPP delay error are also calculated: 
a) Q should be modifed as "quiet day data"

For quiet day data corresponding to 6 July 2004 $(\mathrm{Kp}<2)$, the estimated mean UIPP delay and the mean UIPP delay error values are shown in figure 2. It is observed that the peak value of the estimated quiet day data and measured mean UIPP delays is $5.52 \mathrm{~m}$ and $5.99 \mathrm{~m}$ respectively. It can be observed from the results that the estimated mean UIPP delay follows the measured mean UIPP delay variation with the local time. The mean and standard deviations of UIPP delay error are found to be less than $1.73 \mathrm{~m}$ and $0.86 \mathrm{~m}$ respectively. Large variations are noticed in the UIPP delays around $18.30 \mathrm{hrs}$. These could be mainly attributed to the occurrence of scintillation at these times;

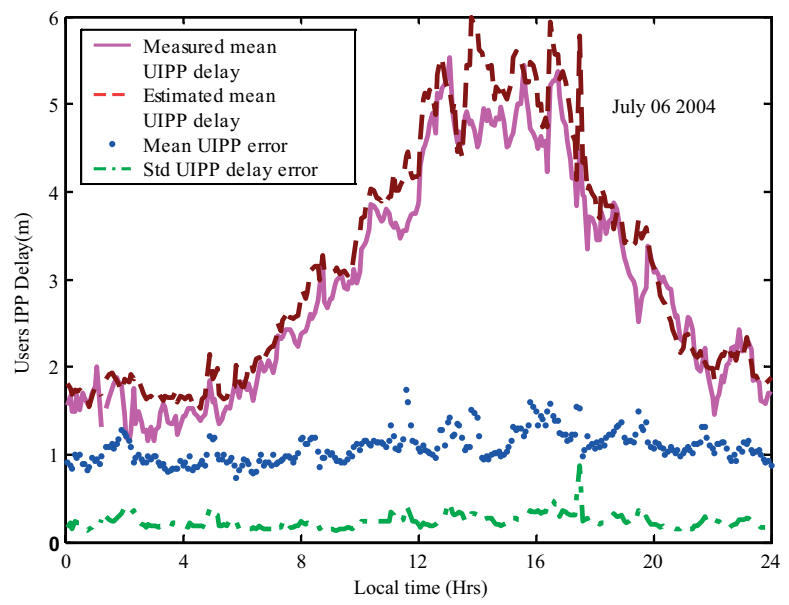

Fig. 2. Estimated mean UIPP delay and mean UIPP delay error using bilinear interpolation technique (6 July 2004)

\section{b) moderate day data}

For a magnetically moderate day on 7 May 2004 $(\mathrm{Kp}<5)$, the estimated mean UIPP delay and the mean UIPP delay error values are shown in figure 3 . It is observed that the peak values of the estimated and measured mean UIPP delays are $9.2 \mathrm{~m}$ and $9.7 \mathrm{~m}$ respectively. It can be observed from the results that the estimated mean UIPP delay closely follows the measured mean UIPP delay variation with the local time. The mean and standard deviation of UIPP delay error are found to be less than $1.82 \mathrm{~m}$ and $0.68 \mathrm{~m}$ respectively. It is evident that the standard deviation of the mean UIPP delay error is lowest for MMSE with the bilinear model;

\section{c) disturbed day data}

For a magnetically disturbed day on 23 July 2004 $(\mathrm{Kp}<8)$, the estimated mean UIPP delay and the mean UIPP delay error values are shown in figure 4 . It is observed that the peak values of the estimated and measured mean UIPP delays are $9.27 \mathrm{~m}$ and $11.04 \mathrm{~m}$ respectively. It can be observed from the results that the estimated mean UIPP delay closely follows the measured mean UIPP delay variation with the local time. The mean and standard deviations of UIPP delay error are found to be less than $3.2 \mathrm{~m}$ and $1.5 \mathrm{~m}$ respectively. It is also observed from figures $2-4$ that the maximum estimated UIPP delay error is $1.73 \mathrm{~m}$ for the quiet day data (6 July 2004). From the results of the data from 6 July $(\mathrm{Kp}<2), 7$ May $(\mathrm{Kp}<5)$ and 23 July $2004(\mathrm{Kp}<8)$, it is evident that the mean UIPP delay and error increases with the increase in the Kp index. The maximum mean UIPP error is $3.2 \mathrm{~m}$ for disturbed day data;

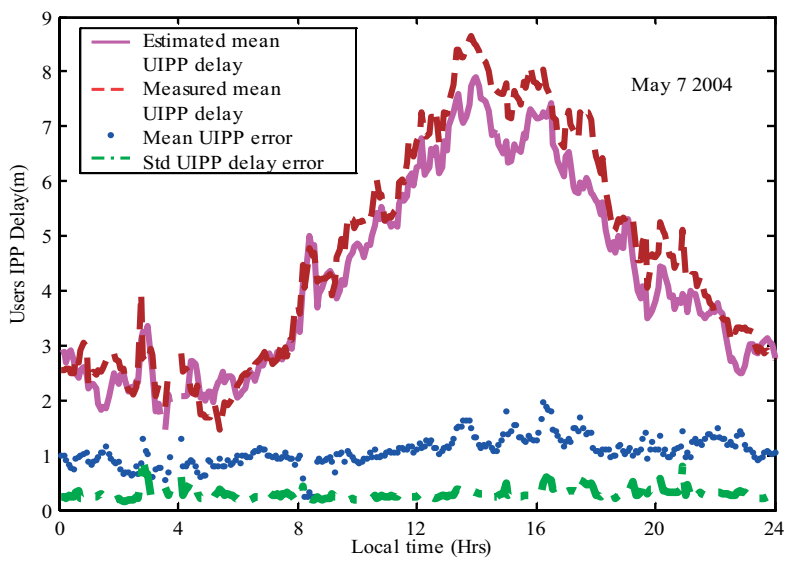

Fig. 3. Estimated mean UIPP delay and mean error using bilinear interpolation technique (7 May 2004)

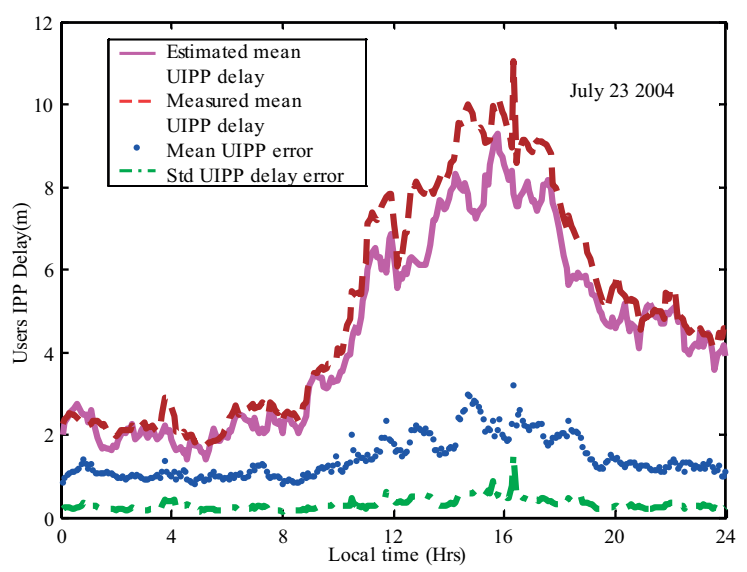

Fig. 4. Estimated mean UIPP delay and mean error using bilinear interpolation technique (23 July 2004)

\section{d) Comparison of bilinear technique with planar fit UPP model}

The bilinear model results are compared to the planar fit user IPP delay estimation algorithm for a typical quiet and disturbed day. Quiet day data corresponding to 8 July 2004 are considered. The estimated mean user IPP delays due to both models are shown figure 5 . The maximum user IPP delay is $4.47 \mathrm{~m}$ for the bilinear technique and $4.57 \mathrm{~m}$ for the planar fit user IPP model. It can be observed that the bilinear model is able to closely follow the planar fit model.

For comparison, disturbed day data corresponding to 23 July 2004 is considered. The estimated mean user IPP delays due to both models are shown in figure 6 . The 
maximum user IPP delay is $11.04 \mathrm{~m}$ for the bilinear technique and $9.39 \mathrm{~m}$ for the planar fit user IPP model. It can be observed that the bilinear model is able to reasonably follow the planar fit model. During the quiet day, it is evident from the results that the maximum estimated mean user IPP delay due to the bilinear model is less compared with the planar fit model.

The bilinear weighting functions have the following two characteristics (Junkins et al. 1973):

1) the sum of all four weights of IGPs is unity;

2) the weight function gives a smooth transition across the boundary of the grid cells.

The bilinear technique is simple and easy to implement in real time environments.

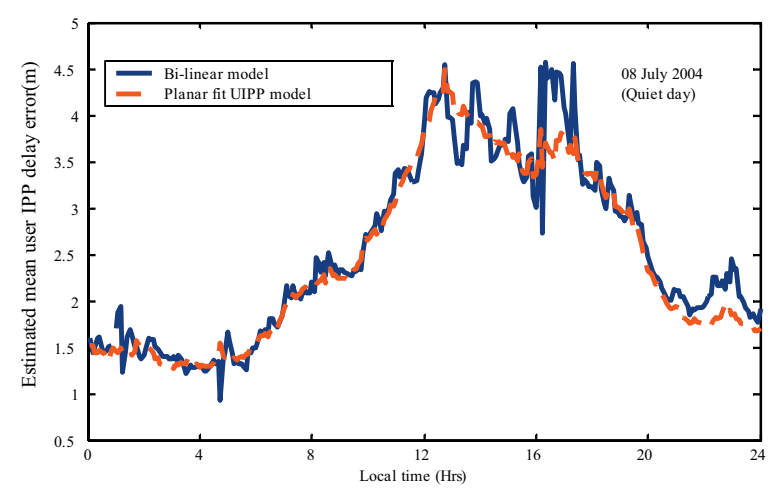

Fig. 5. Estimated mean UIPP delays due to the bilinear interpolation technique and planar fit model (23 July 2004)

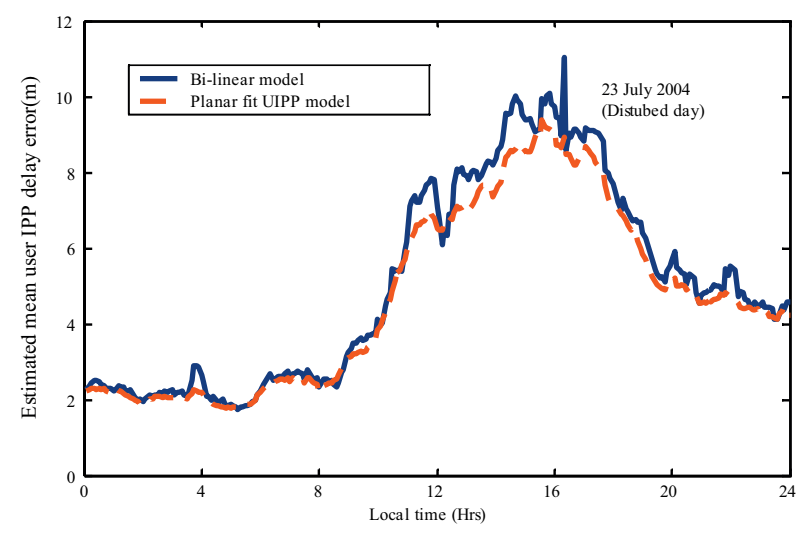

Fig. 6. Estimated mean UIPP delays due to the bilinear interpolation technique and planar fit model (23 July 2004)

\section{Conclusions}

In this paper, an important ionospheric algorithm known as the bilinear model is investigated for user IPP delay estimation. The bilinear model is simple and easy. The estimated user IPP delays are $5.52 \mathrm{~m}, 9.2 \mathrm{~m}$ and $9.27 \mathrm{~m}$ corresponding to quiet, moderate and disturbed days respectively. It is observed that the mean UIPP delay and error increase with the increase in the Kp index. The maximum mean UIPP error is $3.2 \mathrm{~m}$ for disturbed day data (23 July 2004) and $1.73 \mathrm{~m}$ for quiet day data (6 July 2004). The results of the bilinear model are compared with the planar fit model for both quiet and disturbed days. It is observed that the estimated UIPP delay variations of the bilinear model are more than the planar fit model during the disturbed day. The results indicate that the bilinear ionospheric grid algorithm is an effective contender for GAGAN. These models would be useful for modelling ionospheric time delays over the Indian region for GAGAN applications.

\section{Acknowledgments}

The above work has been carried out under the project entitled "Development of Ionospheric Forecasting Models for Satellite-based Navigation Systems over Low Latitude Stations", which is sponsored by the Department of Science and Technology, New Delhi, India, vide sanction letter No: SR/FTP/ETA- 0029/2012, dated: 08.05.12.

\section{References}

Būga, A. 1999. GPS signalų suvèlinimo jonosferoje tyrimas [Investigation of ionospheric dalay of GPS signals], Aviacija. Mokslo darbai [Aviation. Scientific Works] (4): 46-49.

Jakučionis, A. 1997. Kai kurie palydovinių technologijų diegimo navigacijoje klausimai [Some items on the implementation of satellite technologies for navigation], in Tarptautine mokslinè praktiné konferencija, skirta Lietuvos aeroklubo 70-mečiui, AVIACIJA-97. Pranešimu rinkinys [International Scientific Applied Conference devoted to 70 years of Lithuanian Air Club, AVIATION-97. Conference Proceedings]. Vilnius: Technika, 54-55.

Jakučionis, A.; Giniotis, V. 1998. Kai kuriu skirtuminių GPS korekcijų technologijų analizė [Analysis of some GPS differential correction technologies], Aviacija. Mokslo darbai [Aviation. Scientific works] (3): 110-112.

Junkins, J. L.; Miller, G. W.; Jancaits, J. R. 1973. A weighting function approach to modelling of irregular surfaces, Journal of Geophysical Research 78(1): 1794-1803. http://dx.doi.org/10.1029/JB078i011p01794

Kibe, S. V. 2003. Indian plan for satellite-based navigation system for civil aviation, Current Science 84(11): 14051411.

Lejeune, R. M.; El-Arini, M. B.; Klobuchar, J. K., et al. 2002. Adequacy of the SBAS ionospheric grid concept for precision approach in the Equatorial region, in Proceedings of ION GPS, Portland, Oregon, USA: 1330-1349.

Ratnam, D. V., et al. 2011. Performance evaluation of selected ionospheric delay models during geomagnetic storm conditions in low-latitude region, Radio Science 46. http://dx.doi.org/10.1029/2010RS004592

Ratnam, D. V.; Sarma, A. D. 2006. Modelling of Indian ionosphere using MMSE estimator for GAGAN applications, IGU Journal (India), October 2006.

Ratnam, D. V.; Sarma, A. D. 2012. Modelling of low latitude ionosphere using GPS data with SHF model, IEEE Transactions on Geoscience and Remote Sensing. http://dx.doi.org/10.1109/TGRS.2011.2163639

Sarma, A. D. Ratnam, D. V.; Krishna Reddy, D. 2009. Modelling low latitude ionosphere using modified planar fit method for GAGAN, IET Radar Sonar Navigation 3(6): 609-619. http://dx.doi.org/10.1049/iet-rsn.2009.0022 
Sarma, A. D.; Prasad, N.; Madhu. T. 2006 Investigation of suitability of grid-based ionospheric models for GAGAN', Electronics Letters 42 (8): 478-479. http://dx.doi.org/10.1049/el:20063036

Stankūnas, J.; Jakučionis, A.; Petrusevičius, V. 2005. Accuracy and performance of augmentations to global navigation systems, Aviation 9(4): 33-38.

Suryanarayana Rao, K. N.; Pal, S. 2004. The Indian SBAS system, in Proceedings of India United States Conference on Space Science Application and Commerce, June 2004, Bangalore, India.

WAAS MOPS. 1998. Minimum Operational Performance Standards for Global Positioning System-Wide Area Augmentation System Airborne Equipment: RTCA Inc. Document No. RTCA/DO-229B, 6 October 1998. 225 p. 